Edivaldo Aparecido Nunes MARTINS ${ }^{1}$

Raquel Yvonne Arantes

BACCARIN $^{2}$

Correspondência para: EDIVALDO APARECIDO NUNES MARTINS

Centro Universitário Moura Lacerda. Av. Dr. Oscar de Moura Lacerda, 1520 14076510 - Ribeirao Preto - SP eanunes@terra.com.br

Recebido para publicação: 17/08/2004 Aprovado para publicação: 13/02/2006

\title{
Anatomia ultra-sonográfica dos ligamentos patelares de cavalos adultos
}

1 - Curso de Medicina Veterinária do Centro Universitário Moura Lacerda, Ribeirão Preto - SP

2 - Departamento de Clínica Médica da Faculdade de Medicina Veterinária e

Zootecnia da Universidade de São Paulo, São Paulo - SP

\begin{abstract}
Resumo
Para descrever a anatomia ultra-sonográfica foram examinados os ligamentos patelares (medial, intermédio e lateral) e as estruturas relacionadas de 20 articulações fêmuro-tibio-patelares de cavalos adultos. Tanto a ecogenicidade como o alinhamento das fibras de colágeno, a espessura, a forma e relação com as estruturas vizinhas foram avaliadas. Os três ligamentos apresentaram ecogenicidade uniforme e paralelismo das fibras colágenas. Em secção longitudinal os ligamentos patelares medial (LPM) e intermédio (LPI) apresentaram maior espessura do segmento distal $(\mathrm{p}<0,01)$ quando comparado com o proximal. Comparando-se o mesmo segmento entre os três ligamentos, o LPI apresentou espessura maior $(p<0,01)$ em relação ao LPM e ligamento patelar lateral (LPL). Em secção transversal $\left(\mathrm{cm}^{2}\right)$ o LPL apresentou a maior área $(\mathrm{p}<0,01)$, seguido pelo LPI e LPM. Em secção transversal do segmento médio, o LPM apresentou forma triangular, o LPI em forma triangular ou circular, e o LPL formato achatado. As estruturas adjacentes identificadas durante o exame dos ligamentos foram cristas femorais, cartilagem articular, tecido gorduroso periligamentar, patela e tíbia proximal.
\end{abstract}

Palavras-chave:

Ultra-sosonografia.

\section{Introdução}

Os ligamentos patelares medial, intermédio (médio) e lateral unem a patela à região crânio-proximal da tuberosidade da tíbia e fazem parte das estruturas que compõem a articulação femuropatelar, que juntamente com as fermurotibiais formam a articulação fêmuro-tibio-patelar. O ligamento patelar medial (LPM) se insere no aspecto crânio-medial da tuberosidade tibial, sendo que sua margem caudal é confluente com a aponeurose comum dos músculos grácil e sartório. No aspecto proximal, se une a parte proximal do músculo vasto medial. O ligamento patelar intermédio (LPI) se origina no aspecto crânio-distal da patela e corre através do sulco no aspecto crânio-proximal da tíbia, inserindo-se a ela. O ligamento patelar lateral (LPL) está localizado no aspecto crânio-lateral da patela, recebendo uma inserção do músculo bíceps femoral e outra inserção aponeurótica da fáscia lata, inserindo-se finalmente na margem crânio-lateral da tuberosidade tibial ${ }^{1}$.

Os ligamentos patelares são considerados, funcionalmente, uma extensão do grupo muscular quadríceps, auxiliando no mecanismo de repouso dos membros pélvicos $^{2}$. Em posição de repouso, a patela está localizada acima da tróclea femoral, e o LPM com sua fibrocartilagem parapatelar se encaixa acima do chanfrado da crista medial da tróclea femoral. Este mecanismo de encaixe proporciona ao cavalo a manutenção da posição de repouso com mínimo esforço. Quando a articulação fêmuro-tíbio-patelar é flexionada, o músculo quadríceps femoral contrai primeiro para levantar e desencaixar a patela do chanfrado, então ocorre a liberação e deslizamento da 
patela através da tróclea femoral ${ }^{3}$.

Transversalmente, os ligamentos patelares são compostos por feixes de colágeno primário dispostos paralelamente com um número moderado de fibrócitos e vasos sanguíneos de pequeno calibre. Esses feixes primários se agrupam em feixes secundários, separados por um fino septo de tecido conectivo e vasos sanguíneos maiores. A cápsula de tecido conectivo que envolve todo o ligamento é mais densa e fibrosa ${ }^{4}$.

O exame ultra-sonográfico da articulação fêmuro-tíbio-patelar é indicado na avaliação das lesões em tecidos moles e alterações da cartilagem articular sem comprometimento ósseo ${ }^{2}$. Associado ao exame radiográfico é um procedimento de auxílio diagnóstico valioso ${ }^{5}$. Em estudos anteriores, Penninck et al. ${ }^{6}$, em 1990, descreveram pela primeira vez a anatomia ultra-sonográfica da articulação fêmurotíbio-patelar e correlacionaram-na as afecções encontradas na articulação femuropatelar e femurotibial. Denoix et al. ${ }^{3}$ (1994) realizaram estudo comparativo entre as imagens ultra-sonográficas, imagens de ressonância magnética e secções de membros congelados da articulação femurotibial. Dik ${ }^{5}$ descreveu as alterações ultra-sonográficas do joelho enfatizando o uso da ultra-sonografia e comparando-a ao exame radiográfico. Denoix e Lacombe ${ }^{8}$ diagnosticaram e descreveram as lesões de menisco. Cauvin et al. ${ }^{9}$ realizaram exames ultra-sonográficos dos aspectos cranial e caudal da articulação femurotibial, e por fim, Dyson ${ }^{1}$, comparou a aparência ultra-sonográfica do LPI entre cinco cavalos da raça Puro Sangue Inglês (PSI) e cinco cavalos de salto. Além disso, descreveu alterações ultra-sonográficas em nove cavalos com comprometimento clínico nos ligamentos patelares. Finalizando, concluiu que existe considerável variação de tamanho dos ligamentos patelares entre os cavalos, principalmente nos PSI, com menor variação quando se compara os ligamentos patelares do membro direito com o esquerdo do mesmo cavalo.
As lesões dos ligamentos patelares são uma causa potencial de claudicação dos membros pélvicos em eqüinos submetidos à prática esportiva, diagnosticáveis segundo Denoix $^{10}$, durante o exame ultra-sonográfico, através da avaliação do tamanho e da forma dos ligamentos, e demonstradas nos estágios iniciais por um aumento no tamanho devido a hemorragia, edema, ou aumento de conteúdo celular.

Frente a poucos dados referentes à anatomia ultra-sonográfica destas estruturas, principalmente considerando a variabilidade entre animais, este trabalho tem como objetivo caracterizar a anatomia ultrasonográfica dos ligamentos patelares de cavalos adultos.

\section{Materiais e Métodos}

Foram examinadas 20 articulações fêmuro-tibio-patelares de eqüinos adultos, sem raça definida, machos ou fêmeas, pesando entre 350 e $490 \mathrm{~kg}$. Foram escolhidos animais que não apresentavam histórico de lesões e alterações radiográficas, que não demonstravam claudicação após exame físico, e que não responderam ao teste de flexão dos membros pélvicos.

O exame ultra-sonográfico foi realizado com o animal em estação em tronco de contenção próprio para eqüinos. Previamente ao exame, uma ampla área foi tricotomizada e uma camada de gel foi aplicada sobre a pele. Foi utilizado um ultrasom Aloka a, com transdutor linear multifreqüencial $(7,5 \mathrm{MHz})^{\mathrm{b}}$, acoplado a um adaptador de funçãoc .

Durante o exame dos ligamentos patelares foi analisada a ecogenicidade, o alinhamento das fibras de colágeno, a espessura, a forma e a relação com estruturas vizinhas.

Tanto a ecogenicidade como alinhamento das fibras de colágeno dos ligamentos patelares foram analisados conforme preconizado por Genovese et al. ${ }^{11}$. Para aferição da espessura dos ligamentos patelares medial, intermédio e lateral, foram 
Tabela 1 - Valores médios e desvio padrão $( \pm$ DP) da espessura dos ligamentos patelares medial, intermédio e lateral (segmentos proximal, médio e distal - secção longitudinal); perímetro eárea (segmento médio-secção transversal), obtidos através de exame ultra-sonográfico de 20 articulações fêmuro-tíbio-patelares de cavalos sadios. São Paulo, 2004

\begin{tabular}{|c|c|c|c|c|c|}
\hline \multirow[t]{2}{*}{$\begin{array}{c}\text { Ligamentos } \\
\text { Patelares }\end{array}$} & \multicolumn{3}{|c|}{$\begin{array}{l}\text { LONGITUDINAL } \\
\text { Espessura }(\mathrm{cm})\end{array}$} & \multirow{2}{*}{$\begin{array}{c}\text { TRANSVERSAL } \\
\text { Área }\left(\mathrm{cm}^{2}\right) \\
\text { Medio }\end{array}$} & \multirow{2}{*}{$\begin{array}{l}\text { TRANSVERSAL } \\
\text { Perímetro }(\mathrm{cm}) \\
\text { Medio }\end{array}$} \\
\hline & Proximal & Medio & Distal & & \\
\hline Medial & $0,51 \pm 0,11^{\mathrm{Aa}}$ & $0,60 \pm 0,16^{\mathrm{Aab}}$ & $0,68 \pm 0,04^{\mathrm{Ab}}$ & $0,85 \pm 0,292^{A}$ & $4,11 \pm 0,90^{\mathrm{A}}$ \\
\hline Intermédio & $0,74 \pm 0,20^{B a}$ & $0,84 \pm 0,16^{\mathrm{B} a b}$ & $0,94 \pm 0,03^{\text {В } b}$ & $1,12 \pm 0,3^{\mathrm{AB}}$ & $4,23 \pm 0,59^{A}$ \\
\hline Lateral & $0,57 \pm 0,13$ & $0,52 \pm 0,13^{\mathrm{Aa}}$ & $0,62 \pm 0,04^{\mathrm{Aa}}$ & $1,41 \pm 0,571^{\mathrm{B}}$ & $6,13 \pm 1,26^{\mathrm{B}}$ \\
\hline
\end{tabular}

Valores com letras maiúsculas diferentes na mesma coluna indicam diferença significativa ( $p<0,01)$.

Valores com letras minúsculas diferentes na mesma linha indicam diferença significativa $(\mathrm{p}<0,01)$

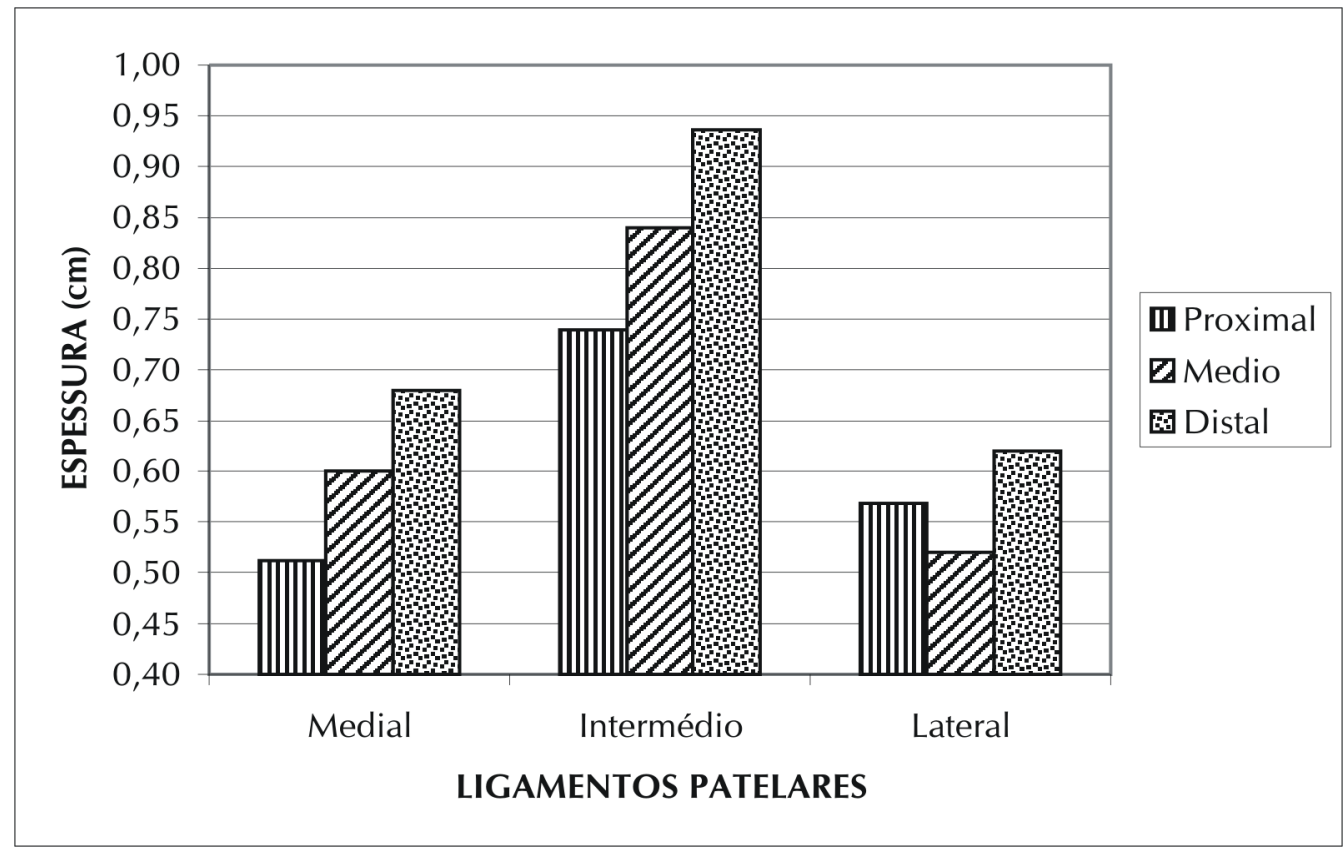

Figura 1 - Representação gráfica das médias da espessura $(\mathrm{cm})$ obtidas na secção longitudinal dos ligamentos patelares medial, intermédio e lateral (segmento proximal, médio e distal), durante avaliação ultra-sonográfica de 20 articulações fêmuro-tíbio-patelares de cavalos adultos.

realizadas secções no sentido longitudinal (cm) dos segmentos proximal, médio e distal; já para aferição da área transversal média $\left(\mathrm{cm}^{2}\right)$ e do perímetro $(\mathrm{cm})$ utilizou-se a secção transversal do segmento médio.

Os dados foram avaliados segundo a normalidade pelo teste de KolmorovSmirnov; em seguida utilizou-se a análise de variância para verificar o efeito de grupos. O contraste entre médias foi feito pela d.m.s. do teste de Tukey a nível de 5\% de probabilidade. A correlação entre as variáveis peso do animal e diferentes espessuras dos ligamenos patelares, área e perímetro foi calculada utilizando-se o teste de Pearson.

\section{Resultados e Discussão}

Os dados referentes aos valores médios da espessura dos ligamentos patelares medial, intermédio e lateral (secção longitudinal), área média e perímetro (secção transversal), nos seus diferentes segmentos estão demonstrados na tabela 1 e figuras 1 e 2 . Quando estes mesmos valores foram comparados entre membro pélvico esquerdo e direito não foram encontradas diferenças estatisticamente significativas $(p>0,05)$. 


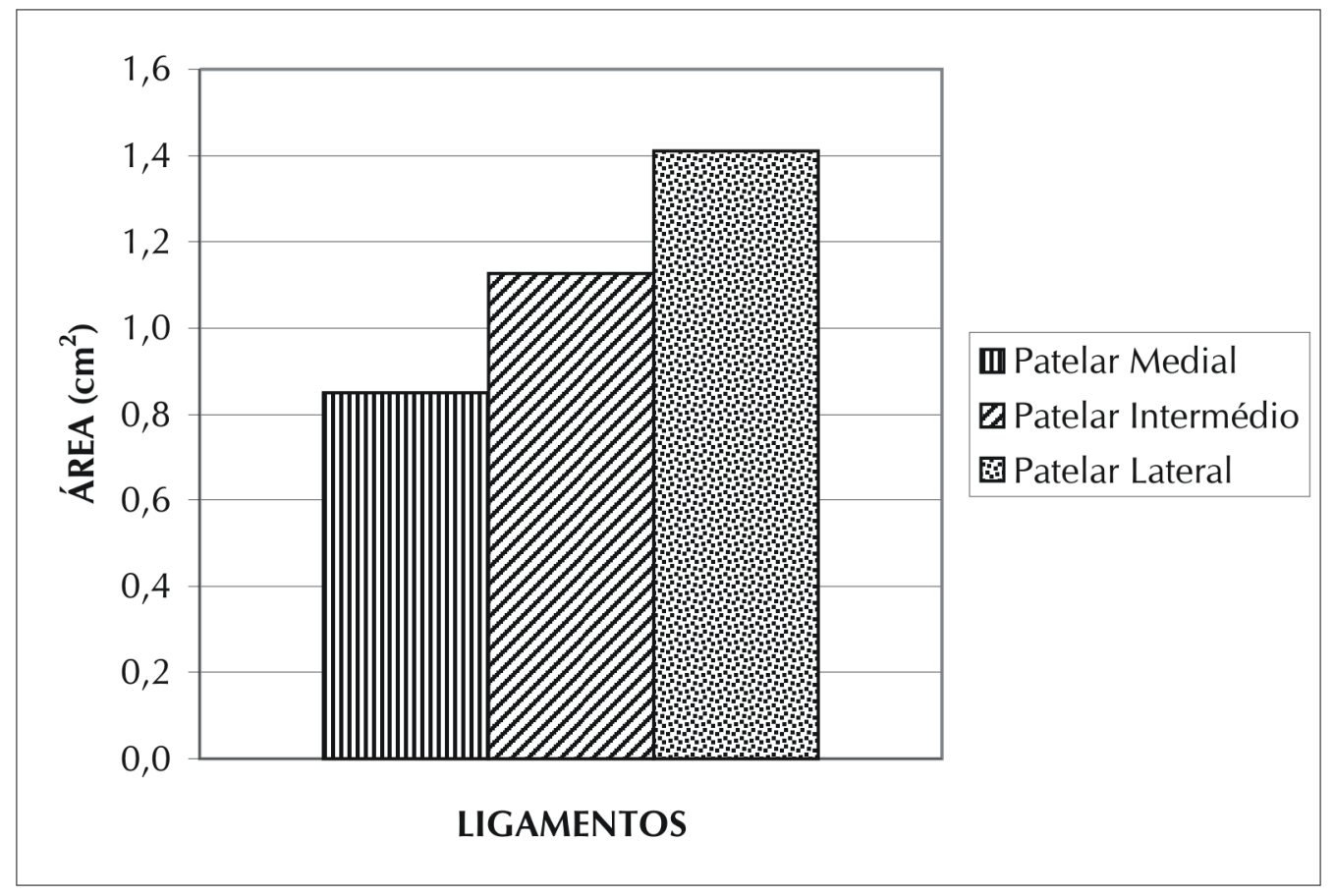

Figura 2-Representação gráfica das médias daárea $\left(\mathrm{cm}^{2}\right)$ obtidas em secção transversal dos ligamentos patelares medial, intermédio e lateral (segmento médio), durante avaliação ultra-sonográfica de 20 articulações fêmuro-tíbio-patelares de cavalos adultos

Correlacionando-se peso dos animais e valores da espessura, área e perímetro dos ligamentos, foi observada correlação positiva média $(r=0,40)$, estatisticamente significativa entre peso e segmento proximal do LPI $(p<0,05)$, e correlação positiva alta $(\mathrm{r}=0,74)$, estatisticamente significativa entre peso e segmento proximal do LPM $(\mathrm{p}<0,001)$, ou seja, quanto mais pesado o eqüino maior será a espessura do segmento proximal do LPI e do LPM, à secção longitudinal do exame ultra-sonográfico.

O exame ultra-sonográfico na secção transversal e longitudinal dos ligamentos patelares demonstrou ecogenicidade uniforme em toda extensão, e alinhamento das fibras colágenas em sentido longitudinal. Durante a realização dos exames, os cavalos permaneceram com o apoio sobre o membro examinado, mantendo-o em extensão. Este posicionamento permitiu a tração dos ligamentos patelares e a correta visualização dos feixes de fibras colágenas. Segundo Denoix ${ }^{10}$ o relaxamento dos ligamentos durante o exame, induz ao enrugamento das fibras nos locais de inserção e os feixes de fibras colágenas expressam ondulações em outras partes intermediárias, levando a formação de artefatos hipoecóicos e comprometimento das imagens.

O transdutor utilizado foi adequado para o exame dos ligamentos patelares, porém, devido à irregularidade da região cranial do joelho e a superficialidade dos ligamentos, optou-se pelo uso do adaptador de função, permitindo a modulação do transdutor a região examinada, além de evitar a formação de imagens distorcidas e possibilitar melhor visualização dos ligamentos. A acomodação do transdutor foi mais fácil no LPI, seguido do LPM e do LPL.

$\mathrm{Na}$ avaliação em secção longitudinal (cm), os ligamentos patelares medial e intermédio, apresentaram aumento da espessura a medida que se distanciaram da patela em sentido a crista tibial. Esta espessura foi significantemente maior 

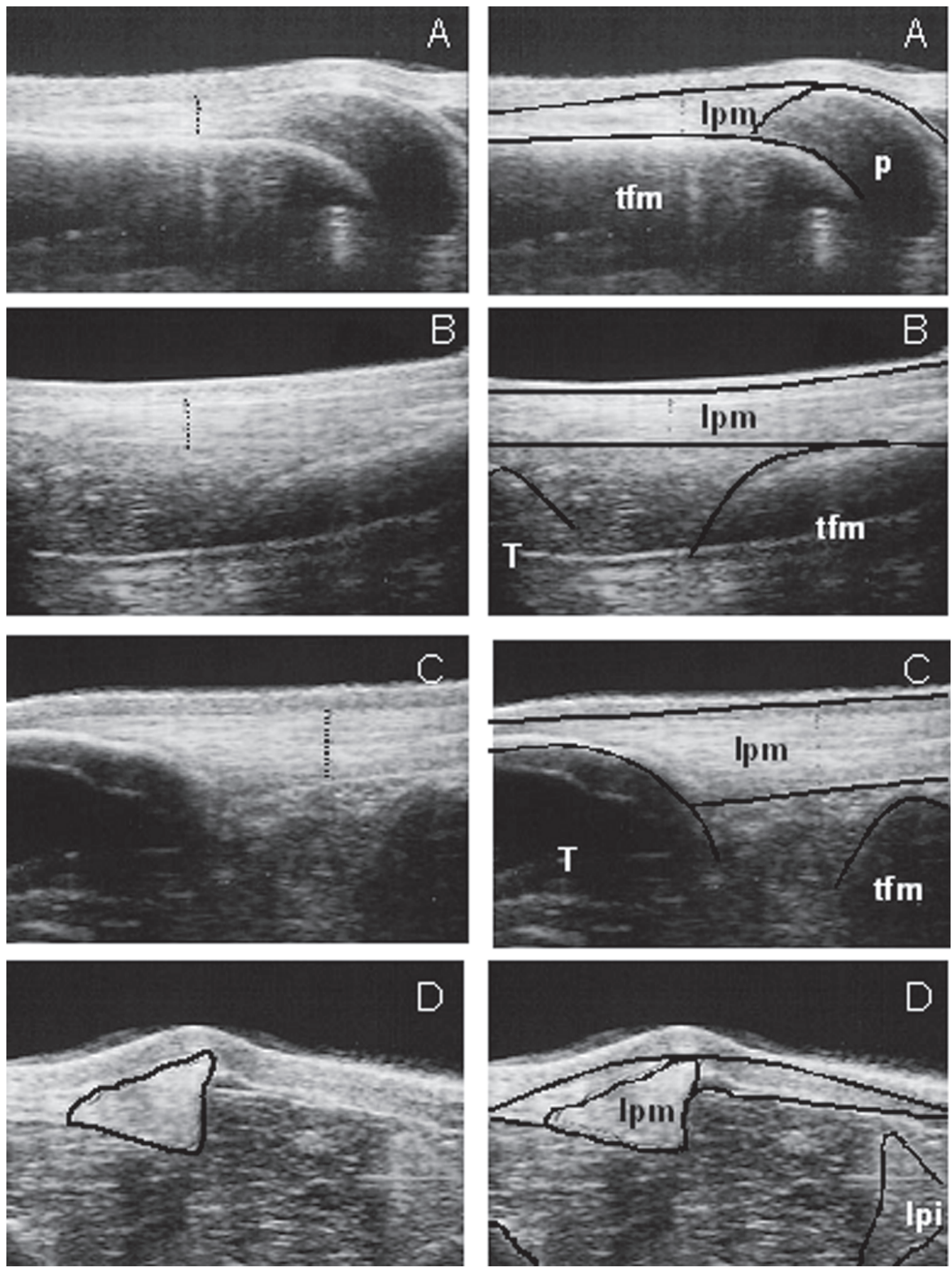

Figura 3 - Imagem ultra-sonográfica longitudinal do ligamento patelar medial. A: local de aferição no segmento proximal (0,37cm). B: local de aferição no segmento médio $(0,58 \mathrm{~cm})$. C: local de aferição no segmento distal $(0,82 \mathrm{~cm})$. Notar a ecogenicidade uniforme do ligamento. D: Imagem ultra-sonográfica transversal do ligamento patelar medial demonstrando o local de aferição no segmento médio (área: $1,09 \mathrm{~cm}^{2} ;$ perímetro: 4,68cm). Ipm - ligamento patelar medial; Ipi - ligamento patelar intermédio; $\mathrm{p}$ - patela; $\mathrm{tm}$ - tróclea femoral medial; $\mathrm{T}$ - tíbia 

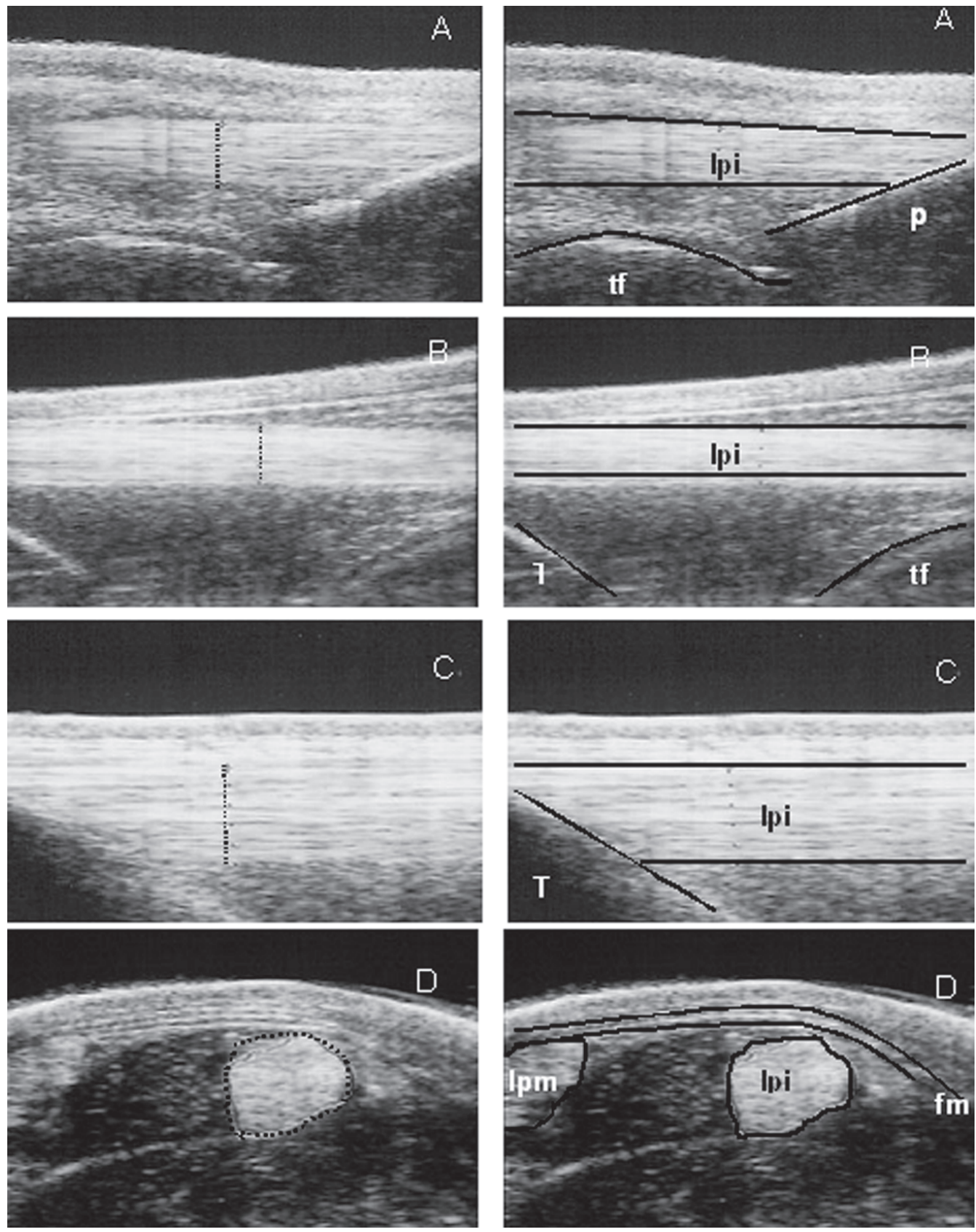

Figura 4 - Imagem ultra-sonográfica longitudinal do ligamento patelar intermédio. A: local de aferição no segmento proximal $(0,75 \mathrm{~cm})$. B: local de aferição no segmento médio $(0,78 \mathrm{~cm})$. C: local de aferição no segmento distal $(0,96 \mathrm{~cm})$. Notar a ecogenicidade uniforme do ligamento. D: Imagem ultra-sonográfica transversal do ligamento patelar intermédio demonstrando o local de aferição no segmento médio (área: $1,26 \mathrm{~cm}^{2}$, perímetro $\left.4,37 \mathrm{~cm}\right)$. fm - fáscia muscular; lpm - ligamento patelar medial; lpi - ligamento patelar intermédio; $p$ - patela; $t \mathrm{f}$ tróclea femoral; $\mathrm{T}$ - tíbia 

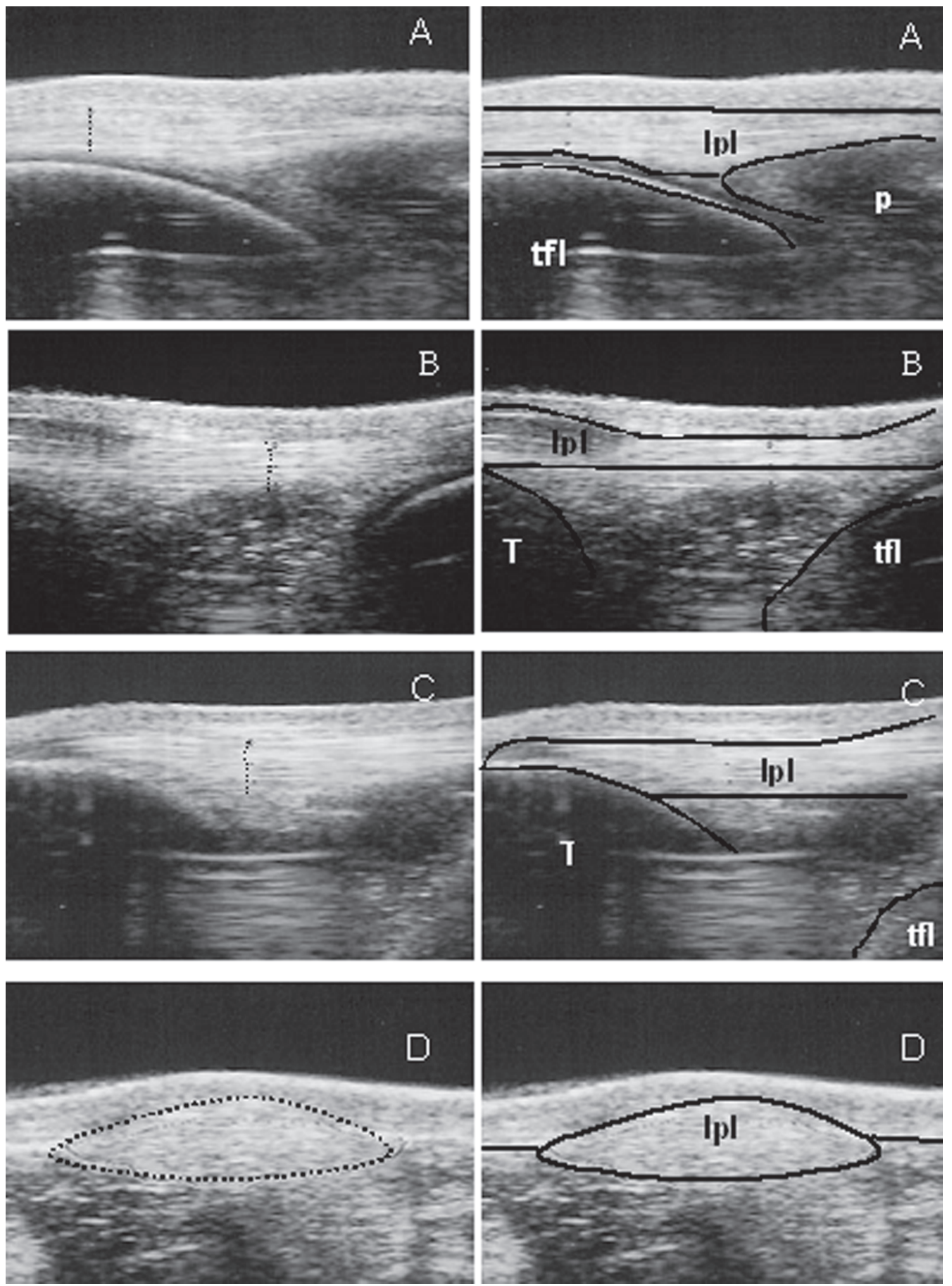

Figura 5 - Imagem ultra-sonográfica longitudinal do ligamento patelar lateral. A: local de aferição no segmento proximal (0,40cm). B: local de aferição no segmento médio $(0,51 \mathrm{~cm})$. C: local de aferição no segmento distal $(0,51 \mathrm{~cm})$. Notar a ecogenicidade uniforme do ligamento. D: Imagem ultra-sonográfica transversal do ligamento patelar lateral demonstrando o local de aferição no segmento médio (área: $1,37 \mathrm{~cm}^{2}$, perímetro: 6,73cm). Ipl - ligamento patelar lateral; p - patela; $\mathrm{tl}$ - tróclea femoral lateral; T - tíbia 
$(\mathrm{p}<0,01)$ no segmento distal quando comparado ao segmento proximal (Tabela 1, Fig.ura 1). Comportamento semelhante foi observado por Dyson ${ }^{1}$ durante avaliação do LPI, porém através de secção transversal $(\mathrm{cm} 2)$ do segmento proximal $(0,78 \pm 0,46 \mathrm{e}$ $0,94 \pm 0,14)$ médio $(0,80 \pm 0,47$ e $0,98 \pm 0,16)$ e distal $(1,07 \pm 0,66$ e 1,42 $\pm 0,11)$ em cavalos sadios. O LPL apresentou espessura maior no segmento distal comparativamente aos outros dois segmentos, contudo sem significância estatística (Tabela 1, Figura 1).

$\mathrm{Na}$ análise comparativa do mesmo segmento entre ligamentos, o segmento proximal do LPI apresentou espessura maior seguida do LPL e do LPM, sendo que a espessura do LPI foi significantemente maior ( $\mathrm{p}<0,01)$ quando comparado ao LPM e LPL. Nos segmentos médio e distal, os ligamentos apresentaram comportamento semelhante, ou seja, o LPI foi o mais espesso seguido do LPM e do LPL, sendo a espessura do LPI significantemente maior ( $\mathrm{p}<0,01)$ quando comparado ao LPM e LPL (Tabela 1, Figura 1).

$\mathrm{Na}$ avaliação em secção transversal $\left(\mathrm{cm}^{2}\right)$ do segmento médio, a área do LPL foi significantemente maior ( $p<0,01$ ), seguida pela área do LPI e LPM (Tabela 1, Figura 2). O mesmo pode ser observado no perímetro dos ligamentos. Estes resultados diferem dos encontrados por Dyson ${ }^{1}$, onde a área do LPI foi maior $(0,80 \pm 0,47$ e $0,98 \pm 0,16)$, seguida pela área do LPL $(0,69 \pm 0,41$ e $0,87 \pm 0,15)$ e do LPM $(0,66 \pm 0,39$ e $0,82 \pm 0,10)$. Dyson ${ }^{1}$ também descreve a presença de grande variação no tamanho destes ligamentos entre cavalos. A diferença encontrada entre os dois trabalhos ocorreu provavelmente porque foram utilizados cavalos com características anatômicas distintas. Observaram-se também médias diferentes para a área dos ligamentos intermédio e lateral.

$\mathrm{Na}$ secção transversal do segmento médio, o LPM apresentou forma triangular, o LPI forma triangular (3/10) ou circular (7/ 10), e o LPL estrutura achatada (Figuras 3D, $4 \mathrm{D}$ e $5 \mathrm{D}$ respectivamente), corroborando os achados de Dyson ${ }^{1}$, que também descreveu a forma da área proximal e distal do LPI como sendo oval ou triangular e triangular, respectivamente. Sugere-se que a área de contato de cada ligamento seja responsável pelas diferentes formas encontradas, podendo-se atribuir ao formato triangular do LPM a concavidade existente na área de transição entre o côndilo femoral medial e a crista troclear medial, o formato triangular ou circular do LPI devido ao seu encaixe a concavidade do sulco troclear; e a forma achatada do LPL devido a área lateral da crista troclear lateral ser plana, e também, à necessidade de maior área para inserção do músculo bíceps femoral e da aponeurose da fáscia lata. Penninck, Penninck et al. ${ }^{6}$, descreveu os três ligamentos como tendo forma oval, não levando em consideração as particularidades de cada área do ligamento e a diferença da forma entre os mesmos.

Durante o exame em secção transversal, também foi observada maior distância entre os ligamentos medial e intermédio, do que entre os ligamentos intermédio e lateral, conforme descrito por Kainer ${ }^{12}$.

Quanto às características da inserção dos ligamentos à patela, o LPM seguiu ao longo da face medial da crista troclear medial como estrutura hiperecogênica, havendo uma diminuição gradativa da ecogenicidade até tornar-se anecóica a medida que se inseria a fibrocartilagem da patela (Figura 3A). O LPI e o LPL apresentaram suas inserções diretamente no osso da patela, demonstradas no sonograma como uma linha hiperecóica (Figuras 4A e 5A respectivamente). Entre os ligamentos patelares intermédio e lateral, e em menor grau ao redor do LPM, observaram-se áreas hipoecogênicas uniformes e difusas identificadas como sendo tecido gorduroso.

Durante a avaliação dinâmica em secção longitudinal, a crista lateral da tróclea femoral foi evidenciada ao exame do LPL com forma côncava (Figura 5A); a crista medial da tróclea femoral com forma achatada foi identificada ao exame do LPM (Figura 3A), sendo também observadas durante a aferição da espessura do segmento médio dos diferentes ligamentos 
(Figura 3B, 4B e 5B). Em secção transversal, o LPI foi identificado entre a crista femoral lateral e medial, sobre o sulco femoral (Figura 4D). A exemplo da descrição ultra-sonográfica, realizada por Penninck et al. ${ }^{6}$, as cristas e o sulco femoral foram observadas abaixo do LPI e identificados por uma linha hipoecóica contornada por duas interfaces hiperecóicas. A linha hiperecóica cranial representa a interface entre o tecido mole e a cartilagem, e a caudal representa a interface entre a cartilagem hipoecóica e o osso subcondral.

Todos os ligamentos apresentaram inserção óssea à tibia caracterizada por uma linha hiperecóica. Ao redor dos três ligamentos, observou-se interposição mais difusa de tecido adiposo, representada por área hipoecogênica, quando comparada à área proximal (Figuras 3C, 4C e 5C).

\section{Conclusões}

O LPM e LPI aumentam em espessura à medida que se distanciam da patela, sendo que o LPI apresenta-se sempre mais espesso que os outros na secção longitudinal do exame ultra-sonográfico;

$\mathrm{Na}$ secção transversal do segmento médio o LPM apresenta forma triangular, o LPI apresenta forma triangular ou circular, e o LPL apresenta forma achatada;

Na secção longitudinal a crista lateral da tróclea femoral apresenta forma côncava, já a crista medial apresenta forma achatada, e o LPI é identificado entre a crista lateral e medial, sobre o sulco femoral;

O LPM torna-se gradativamente anecóico à medida que se insere a fibrocartilagem da patela;

A inserção do LPI e do LPL à patela é caracterizada por uma linha hiperecóica, bem como a inserção dos ligamentos patelares à tíbia.

\section{Agradecimentos}

$$
\text { projeto. }
$$

À FAPESP pelo financiamento do

\section{Ultrasonographic anatomy of the patellar ligaments in the adults horses}

\section{Key-words:}

Ultrasonography. Patellar ligaments. Equine. Femorotibiopatellar joint. femorotibiopatellar joints of adult horses were investigated. Echogenicity, collagen fibers alignment, size, shape and surrounding structures were evaluated. All ligaments presented uniform echogenicity and collagen fibers parallelism. The longitudinal section of the medial and middle patellar ligaments presented a significant larger thickness $(p<0,01)$ of the distal region when compared to the proximal region. When comparing the same site between the three ligaments, LPI was thicker $(\mathrm{p}<0,01)$ than lateral patellar ligament $(\mathrm{LPL})$ and LPM. The LPL transversal section $\left(\mathrm{cm}^{2}\right)$ presented a significant larger area $(p<0,01)$, followed by the LPI and LPM. The transversal section of the medium region revealed a LPM with triangular shape, triangular or circular LPI, and flattened LPL. The surrounding structures observed during the evaluation were: femoral groove, articular cartilages, periligamentar fat tissue, patella and proximal tibia.

\section{Referencias}

1 DYSON, S. J. Normal ultrasonographic anatomy and injury of the patellar ligaments in the horse. Equine Veterinary Journal, v. 34, n. 3, p. 258-264, 2002.
2 LATIMER, F. G.; KANEPS, A. T.; PASQUINI, C. Stifle disease in horses. Compendium Continum Education Practice Veterinary, v. 22, n. 4, p. 381-340, 2000.

3 TNIBAR, A. M. Medial patellar ligament splitting for the treatment of upward fixation of the patella in 
7 equids. Veterinary Surgery, n. 31, p. 462-467, 2002.

4 VAN HOOGMOED, L. M. Ultrasonographic and histologic evaluation of medial and middle patellar ligaments in exercised horses following injection with ethanolamina oleate and $2 \%$ iodine in almond oil. American Journal of Veterinary Research, v. 63, n. 5, p. 738-743, 2002.

5 DIK, K. J. Ultrasonography of the equine stifle. Equine Veterinary Education, v. 7, n. 3, p. 154-160, 1995.

6 PENNINCK, D. G. et al.. Ultrasonography of the equine stifle. Veterinary Radiology, v. 31, n. 6, p. 293298, 1990.

7 DENOIX, J. M. et al. Ultrasound examination of the femorotibial joint in the horse. Proceedings American Association of Equine Practicioners, v. 40, p. 57-58, 1994.

8 DENOIX, J. M.; LACOMBE, V. Ultrasound diagnosis of meniscal injuries in horse. Pferdeheilkunde, v. 12, n. 4, p. 629-631, 1996.

9 CAUVIN, E. R. J. et al. Ultrasonographic examination of the femorotibial articulation in horses: imaging of the cranial and caudal aspects. Equine Veterinary Journal, v. 26, n. 4, p. 285-296, 1996.

10 DENOIX, J. M. Diagnostic techniques for identification and documentation of tendon and ligaments injuries. Veterinary Clinics of North America: Equine Practice, v. 10, n. 2, p. 365-407, 1994.

11 GENOVESE, R. L. et al. Diagnostic ultrasonography of equine limbs. Veterinary Clinics of North America: Equine Practice, v. 2, p. 127-44, 1986.

12 KAINER, R. A. Functional anatomy of equine locomotor organs. In: STASHAK, T. S. Adam's lameness in horses. 5. ed. Philadelphia: Lea \& Febiger, 2002. p. 1-72. 